\title{
Smart Management Platform for Landfilling of Waste after Mechanical Biological Treatment
}

\author{
Qiaona Wang $\mathbb{D}$, Zhenying Zhang $(\mathbb{D}$, Min Wang $\mathbb{D}$, and Bang Wang $\mathbb{E}$ \\ School of Civil Engineering and Architecture, Zhejiang Sci-Tech University, Hangzhou 310018, China \\ Correspondence should be addressed to Zhenying Zhang; zhangzhenyinga@163.com
}

Received 6 October 2021; Revised 29 December 2021; Accepted 10 January 2022; Published 31 January 2022

Academic Editor: Jorge Branco

Copyright (C) 2022 Qiaona Wang et al. This is an open access article distributed under the Creative Commons Attribution License, which permits unrestricted use, distribution, and reproduction in any medium, provided the original work is properly cited.

\begin{abstract}
With the rapid development of the economy and society, the production of municipal solid waste is continuously increasing worldwide. Therefore, harmless treatments and the disposal of municipal solid waste should be improved. This study combined the concept of Internet of things and smart environment protection with a "cloud, network, end" platform architecture to construct a smart management platform for the planning and management of landfills. The platform was developed for the mechanical biological treatment (MBT) of landfills and was divided into seven modules, landfill design, municipal solid waste production prediction, MBT waste microbial volume reduction, stability analysis, result analysis, remote monitoring, and sharing and communication, which can effectively improve the operation and management of waste, enhance the effective storage volume of a landfill, extend its service life, and thereby improve the sustainable development of the city. This study can be used as a reference for applications in similar projects worldwide.
\end{abstract}

\section{Introduction}

Municipal solid waste (MSW) refers to solid and semisolid waste produced from people's daily activities or production processes, and it mainly includes kitchen residues, bricks and tile residues, paper, plastics, and yard and garden waste [1]. According to the World Bank, with the accelerating urbanisation, population growth, and economic development, global waste production is expected to reach 2.59 and 3.4 billion metric tons by 2030 and 2050, respectively. The fastest growth is expected to occur in sub-Saharan Africa and South Asia. Waste production in these two regions is expected to double by 2050 , which would account for $35 \%$ of the world's total waste production [2]. To mitigate the rapid growth in domestic waste production, source reduction and end disposal have been actively promoted worldwide. However, end treatments such as landfilling and waste incineration often lead to environmental and social conflicts owing to their effects on nearby areas.

In recent years, the life cycle management of domestic waste has attracted increasing attention, especially in Europe and the United States [3]. To reduce the impact of domestic waste disposal on the population, strategies combining the Internet of Things and smart environmental protection have been developed. For example, the New York government has used the Internet of Things technology to upload real-time data on domestic waste pollutants collected by sensors in the Hudson River for efficient ecological management [4]. The Florida Marine Research Organization has built a sensor platform called MARVIN, which provides timely water quality information related to eutrophication and harmful algae [5]. City Sense is a wireless sensor network project jointly developed by Harvard University, the BBN company, and the National Natural Science Foundation of the United States, and it can report monitoring data from an entire city so that the public and scholars can track the diffusion of MSW pollutants through the website [6]. In Hammarby City, Sweden, a computer-controlled waste transportation system has been developed, in which domestic waste is automatically separated and transported to different containers for recycling on demand [7]. The Recycle Bank in the United States has used the Internet of Things and low-frequency radio frequency identification tags on recycling bins to implement a waste collection incentive plan and encourage consumers to 
actively participate in the recycling of waste products [8]. A Finnish company developed a waste recycling system named "Enevo One" based on ultrasonic sensors, which allow managers to intuitively understand the filling status of each waste can in the jurisdiction and plan the best recycling routes for the vehicles, to save operating costs. Osiris is a comprehensive plan under the Global Monitoring for Environment and Security (GMES) programme of the European Union, and it includes a set of integrated information infrastructure for the effective management of environmental pollution in Europe. It provides pollutant monitoring and disaster prevention through a sensing network and on-site monitoring systems. The municipal waste management department of Dubai has used a fleet of unmanned aerial vehicles to supervise littering throughout the city [3]. The University of Basel, the University of Zurich, and the Federal Institute of Technology of Zurich have conducted long-term monitoring of geological and environmental pollution in the Swiss Alps using wireless sensing technology and the Internet of Things in the Perma Sense Project [3].

In China, the development of domestic waste treatment technology has been relatively slow. In the middle and late 1980 s, the country began to plan and prepare for the construction of standard domestic waste landfills. Currently, there are 1,748 sanitary landfills in the country. There can be challenges in the construction and management of domestic waste landfill platforms, such as incomplete on-site infrastructure, insufficient dynamic data, and untimely adjustments to system parameters, which can lead to system collapse and environmental pollution accidents [9].

In the development of landfills, attention should be paid to antiseepage facilities, leachate treatment, landfill gas purification and recovery, and site closure and reuse. Among them, antiseepage facilities specifically refer to laying horizontal barriers, such as a geomembrane and clay liner, at the bottom of the foundation of the landfill to block the migration of leachate in the plant area. In the operation and management of landfills, efforts must be devoted to solving problems such as landfill instability, groundwater pollution, and gas leakage, which can significantly threaten the operation and safety of landfills [10]. In this context, smart management platforms can be used to improve these aspects of landfill planning and management.

Smart management platforms are widely used in tunnel, mining, petroleum, and rail transit engineering in China; however, they are still not widely used for landfill smart management. The Shanghai Laogang comprehensive landfill digital management platform is the only smart management platform that has been built in China. Considering the operation and management requirements of sanitary landfills and the technological aspects involved, this study proposes a smart management platform that combines the Internet of Things and smart environmental protection for the landfilling of waste from mechanical biological treatment (MBT). The platform is expected to accelerate the development of the environmental protection industry and promote the deep integration of the Internet of Things and environmental protection industry to provide a reference for the construction of smart landfill management platforms.

\section{Basic Principles}

2.1. MBT Technology. MBT comprises mechanical and biological treatments, and it can be used alone or in combination with other methods, such as incineration and landfilling. The mechanical part of MBT mainly includes the separation and screening of high-combustion-value components, such as plastics, paper, and wood. However, the main features of biological treatment are aerobic degradation, anaerobic fermentation, or a combination of the two. MBT separates biomass and fuel from domestic and kitchen waste and uses anaerobic digestion technology to convert organic waste into energy. The combustible part is processed to become a high-calorific-value fuel.

MBT systems include mechanical pretreatment, biological hydrolysis, wet anaerobic digestion, biological drying, energy utilisation, odour control, and sewage treatment. The MBT process is illustrated in Figure 1. The fresh domestic waste in the unloading hopper is transported to a drum screen with a diameter of $120 \mathrm{~mm}$ through a conveyor belt for bag breaking and screening. Large pieces of cardboard, plastics, and textiles are recycled by manual selection. After the magnetic suction of large metal materials, the remaining material under the screen is placed in a leaching reactor for hydrolysis, acidification, and dehydration to meet the required average and fixed moisture contents. Finally, the MBT waste material is obtained [11].

2.2. Development of a System Combining Internet of Things and Smart Environmental Protection. The overall architecture of the system combining the Internet of Things and smart environmental protection included perception, transport, service, and application layers [6] as follows:

(1) Perception layer: this layer uses devices, systems, or processes that can sense, measure, capture, or transmit information anytime and anywhere to capture a more thorough perception of environmental factors, such as environmental quality, pollution sources, ecology, and radiation.

(2) Transport layer: this layer combines an environmental protection network and operator network with $5 \mathrm{G}$, satellite communication, and other technologies to share the environmental information stored in personal electronic devices, organisations, and government information systems to achieve more comprehensive interconnection.

(3) Service layer: this layer uses the cloud service mode to establish an object-oriented business application system and information service portal that can provide smarter decisions for cloud operating systems, including those for environmental quality, pollution prevention, ecological protection, and radiation management.

(4) Application layer: this layer integrates and analyses a high amount of cross-regional and cross-industrial environmental information by means of cloud computing, virtualisation, and high-performance 


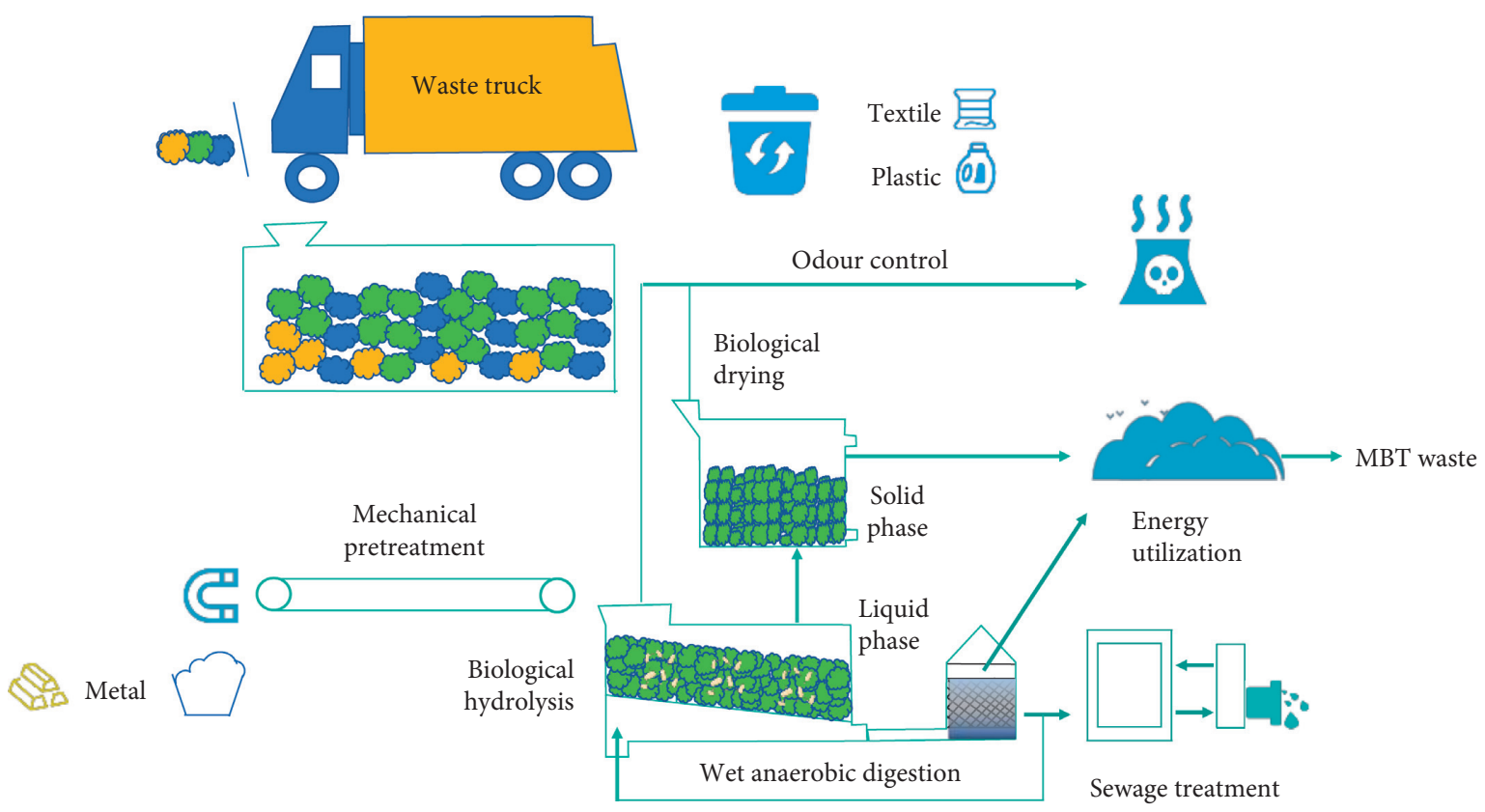

FIgURE 1: Mechanical biological treatment (MBT) process.

computing. This layer also provides significant data storage, real-time processing, deep mining, and model analysis ability, as well as more in-depth and intelligent options for the operation and processing of intelligent terminal devices.

\subsection{Big Data Application}

2.3.1. Distributed Computing Platform Hadoop. Hadoop is a distributed system infrastructure developed by the Apache Foundation and can be used to develop distributed programmes without the need to understand the underlying details of the distributed system while fully utilising the cluster power for high-speed computing and storage. The core technologies of the Hadoop distributed platform are the Hadoop Distributed File System (HDFS), MapReduce, Hive, and HBase. The bottom structure is the HDFS, which stores files on all storage nodes in the Hadoop cluster [12].

2.3.2. Distributed Hadoop Database (HBase). HBase is an open-source column-oriented database that is suitable for storing massive unstructured data or semistructured data, with high reliability, high performance, and flexible scalability. It can support real-time data reading and can be used to develop distributed storage systems. Using HBase technology, a large-scale structured storage cluster can be built on a PC server [13].

\subsubsection{Distributed Search Engine Elasticsearch.} Elasticsearch is a distributed, high-expansion, high-realtime search, and data analysis engine, which can be used to develop several datasets that can be searched, analysed, and explored. HBase is a database run on the basis of the Hadoop cluster. It can achieve a faster processing speed and larger volume owing to the atomicity, consistency, isolation, and persistence of traditional databases. By fully utilising the horizontal scalability of Elasticsearch, more valuable data can be obtained in the production environment [14].

2.3.4. Big Data Architecture System. The concept of a big data architecture system can be summarised as "cloud, network, and end," where "cloud" refers to cloud computing and big data infrastructure, "network" refers to the "original Internet" and "Internet of Things," and "end" refers to the applications in the form of personal computers, mobile devices, wearable devices, sensors, and even software that can be directly operated by users. "End" is the source of data and the interface of service provision [15]. This "cloud, network, end" architecture realises the innovation, transformation, and upgrading of the Internet of Things in combination with other fields, such as traditional industries. The developed platform adopts the "cloud, network, end" big data architecture system and uses modular design as the guiding principle to meet the needs of different business scenarios. That is, the "cloud, network, end" architecture collects data through an intelligent hardware terminal perception device and forwards these data to an intelligent data centre for data insight and algorithm application services.

\section{Platform Design and Application}

3.1. Platform Function Module. Guided by the actual needs of users, the landfill smart management platform aims to provide convenient, practical, and efficient tools for users. The platform is mainly composed of the following modules: landfill design, MSW production prediction, MBT microbial volume reduction, stability analysis, result analysis, remote monitoring, and sharing and communication. 
3.1.1. Landfill Design. This module is used to meet the needs of different business scenarios and provide personalised services. The design of the landfill site includes terrain environment, soil layer information [16, 17], site size parameters [18-22], load parameters [23-26], material parameters [27, 28], and other data [29].

3.1.2. Prediction of MSW Production. The grey system theory is a comprehensive theory that was proposed in 1982, which mainly includes system analysis, information processing (generation), modelling, prediction, decision making, and control. In this module, the $\operatorname{GM}(1, n)$ and ridge regression models are combined into a multivariate prediction model using the optimal weight distribution method to predict the MSW production over the next 5 years.

3.1.3. MBT Microbial Volume Reduction. By importing the main mechanical parameters of MBT waste, such as compression strain, shear strength, and permeability coefficient data, this reduction module can estimate the MBT microbial volume reduction.

3.1.4. Stability Analysis. This module calculates and analyses the factors that affect the stability of landfills, such as the leachate level, heavy rainfall, slope, landfill height, and shear strength.

3.1.5. Result Analysis. This module calculates the safety factor of the most dangerous sliding surface and the safety factor under the traditional limit equilibrium method to provide the limit state hypothesis analysis and early warning, respectively.

3.1.6. Remote Monitoring. This module monitors the landfill site in real time through a base station, intelligent instruments, video monitoring, and other equipment, and it provides an abnormal alarm. Managers can use desktop computers and mobile devices for practical monitoring and management.

3.1.7. Sharing and Communication. Users can log into the system after registration and approval by the administrator. In addition to providing information, browsing, and exchanging information, users can communicate and discuss problems and upload photos.

\subsection{Platform Application}

3.2.1. Landfill Design. In the landfill design interface, there were six modules as follows: topographic environment, soil layer information, landfill data input, material parameter value, slope, and model size design of a three-dimensional slope. The interface diagram of the landfill design is shown in Figures 2 and 3.

The platform was based on the domestic waste mechanical biological ablation technology (EMBT) project jointly developed by Hangzhou Environment Group Co., Ltd. and Jiangsu Welly Environmental Protection Technology Co., Ltd. from Germany, and applied in the Hangzhou Tianziling Circular Economy Industrial Park. At present, the project is still in the pilot stage, but it is operating well.

The Hangzhou Tianziling landfill site was the first standardised valley-type landfill site in China. It is a branch of the Tianmu Mountain and has low and gentle hills. The general elevation is $150-200 \mathrm{~m}$, the elevation of the main peak mountain is $361.24 \mathrm{~m}$, and the mountain trend is $40-50^{\circ}$ northeast. The Hangzhou Tianziling landfill site starts at an elevation of $+50.5 \mathrm{~m}$, height of $12.5 \mathrm{~m}$, and design slope of $1: 3$. As each platform was designed with a raceway, when the final design elevation reached $+165 \mathrm{~m}$, the actual slope of the landfill site was $1: 3.9$ [30].

3.2.2. MSW Production Prediction. In this module, GM $(1, n)$ and ridge regression models were used to develop a multivariate mixed model. According to the correlation degree, the module can analyse many factors influencing MSW output, such as domestic waste production, number of households, per capita consumption expenditure, total retail sales of commodities, total number of tourists, number of university graduates, and real estate investment.

In the prediction interface of the MSW output, the user should input specific data on the influencing factors to obtain the predicted MSW production for the next 5 years and a data comparison chart. The interface diagram of the MSW production prediction is shown in Figure 4.

3.2.3. MBT Microbial Volume Reduction. In this module, the MBT landfill characteristics are combined with the landfill site conditions. The Tianziling landfill is a valley-type landfill site located in a hilly area with a longitudinal size of $165 \mathrm{~m}$. The burying of MBT waste increases the strength of the landfill owing to the high pressure, which creates a significant reduction in the compression volume. Therefore, waste should be landfilled at $0-100 \mathrm{~mm}$.

The preselected parameters, such as compression strain, shear strength, and permeability coefficient, were inputted into the platform to obtain the volume reduction rate of MBT waste in different states. As shown in Figure 5, the volume reduction of fresh domestic waste at $0-100 \mathrm{~mm}$ by MBT technology was $56 \%$, and it could be increased to $80 \%$ with precompression. The main compression treatment (particle crushing and compression) was then analysed, and the volume reduction rate increased to $89.6 \%$. Finally, the total volume reduction rate reached $90.1 \%$ after the secondary compression treatment.

3.2.4. Stability Analysis. Leachate level analysis is crucial for landfill stability analysis. In addition to leaching risks, a high leachate level can cause landfill instability, groundwater pollution, and landfill gas leakage. To ensure the stability of the landfill and reduce leachate leakage and pollution, the leachate level should be monitored in real time, and engineering measures should be adopted to reduce the leachate level. 


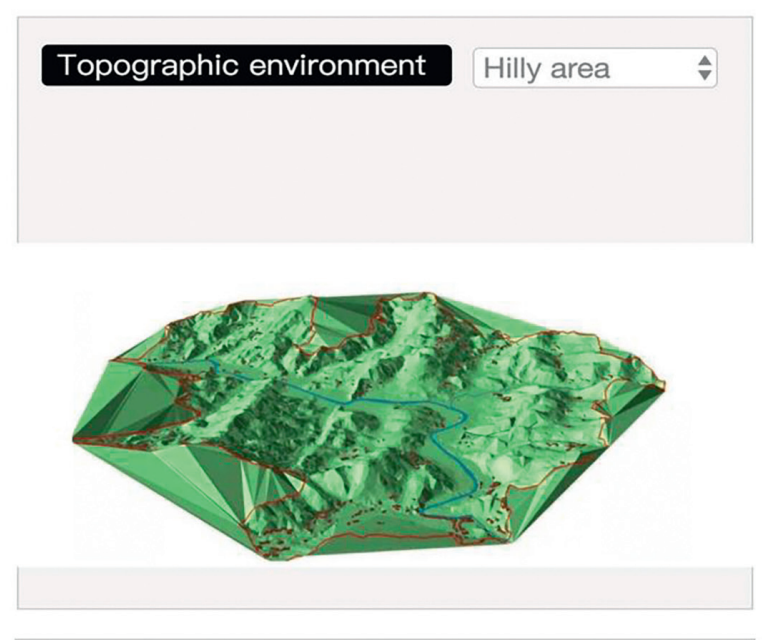

Size parameters of landfills to be built

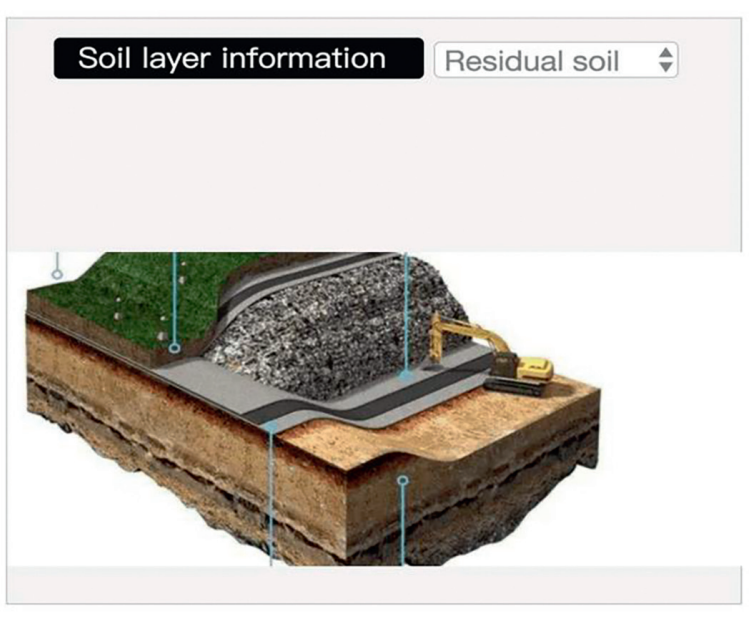

Load parameter

\section{Next}

FIgURE 2: Landfill parameter input.

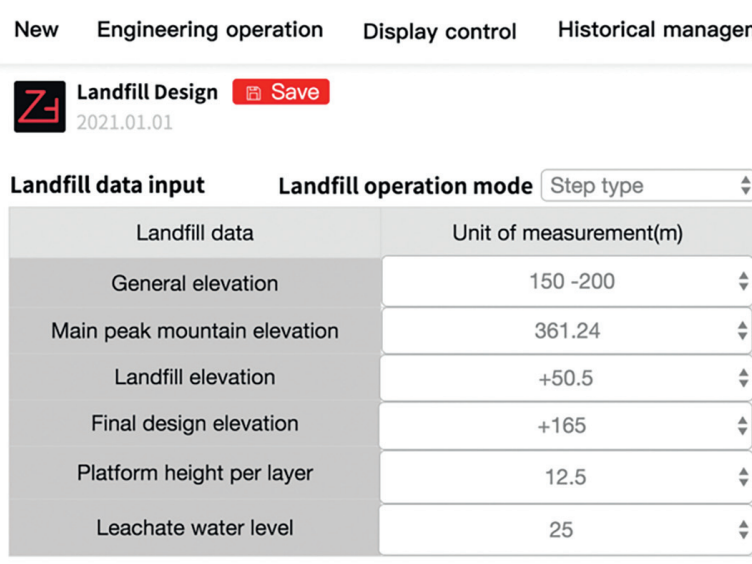

Help

Account number $\& \quad-0 \times$

Model size design of three-dimensional slope

\begin{tabular}{|c|c|c|c|c|c|c|}
\hline Slope size & \multicolumn{6}{|c|}{ Parameter changes } \\
\hline Slope height (m) & 10 & 20 & 30 & 40 & 50 & 60 \\
\hline Top width (m) & $2 \mathrm{H}$ & $4 \mathrm{H}$ & $6 \mathrm{H}$ & $8 \mathrm{H}$ & $10 \mathrm{H}$ & - \\
\hline Slope thickness $(\mathrm{m})$ & 0 & $5 \mathrm{H}$ & $10 \mathrm{H}$ & $15 \mathrm{H}$ & - & - \\
\hline Slope ratio & $1: 2.0$ & $1: 2.5$ & $1: 3.0$ & $1: 3.5$ & $1: 4.0$ & - \\
\hline
\end{tabular}

Figure 3: Landfill design.

Continuous heavy rainfall has a significant effect on the moisture content of waste, which can affect the pore water pressure and matric suction. With continuous rainwater infiltration, the water levels constantly increase and the unsaturated area and matric suction gradually decrease, which would reduce landfill stability. Therefore, the effect of rainfall on landfill stability can be reduced by antiseepage treatments and creating a covering layer on the landfill surface [16].

Landfill slopes can significantly affect operation safety. In actual landfilling, an exceedingly small slope can reduce the storage volume of the landfill, whereas a steep slope can 


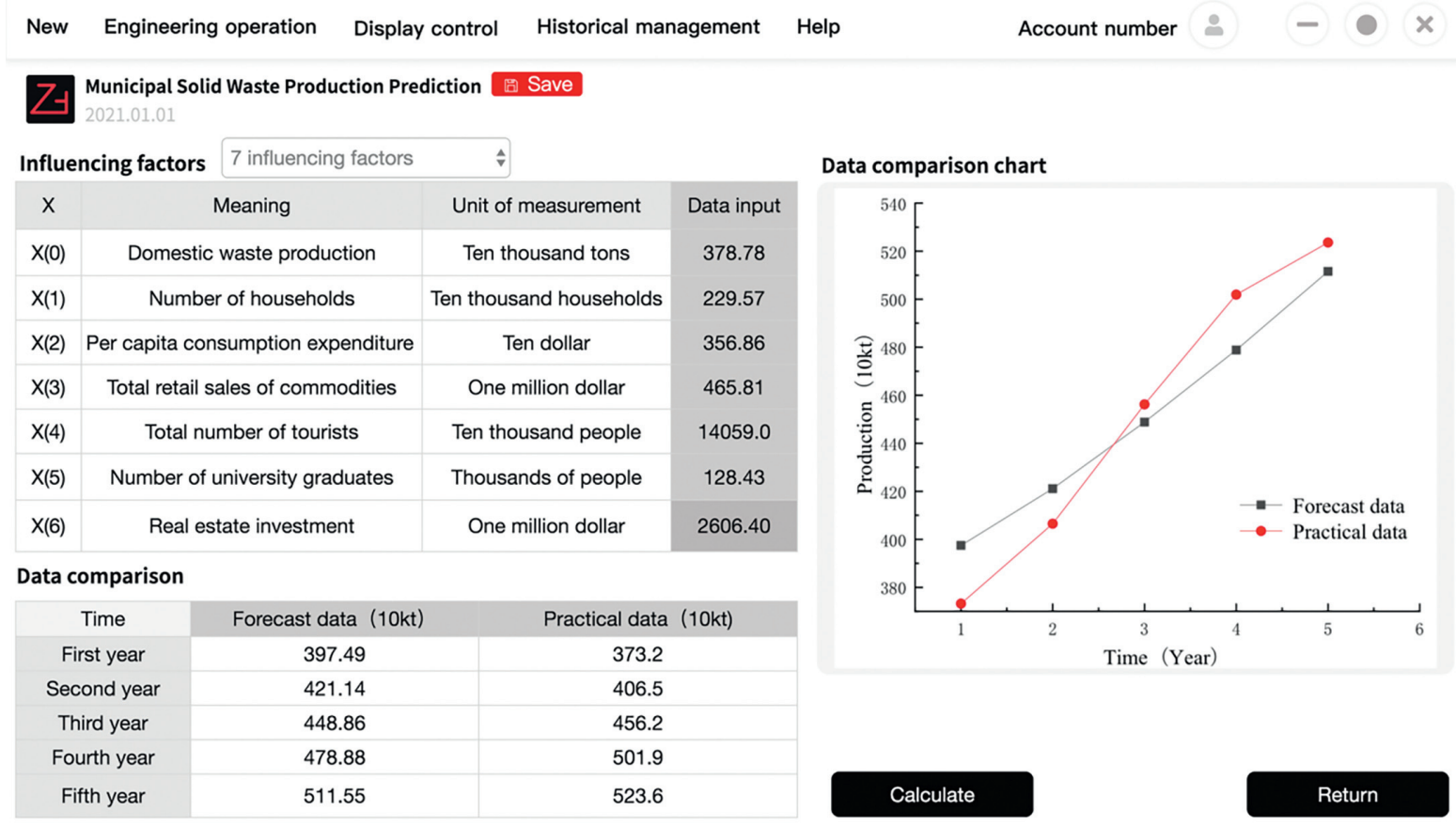

FIGURE 4: Municipal solid waste (MSW) production prediction.

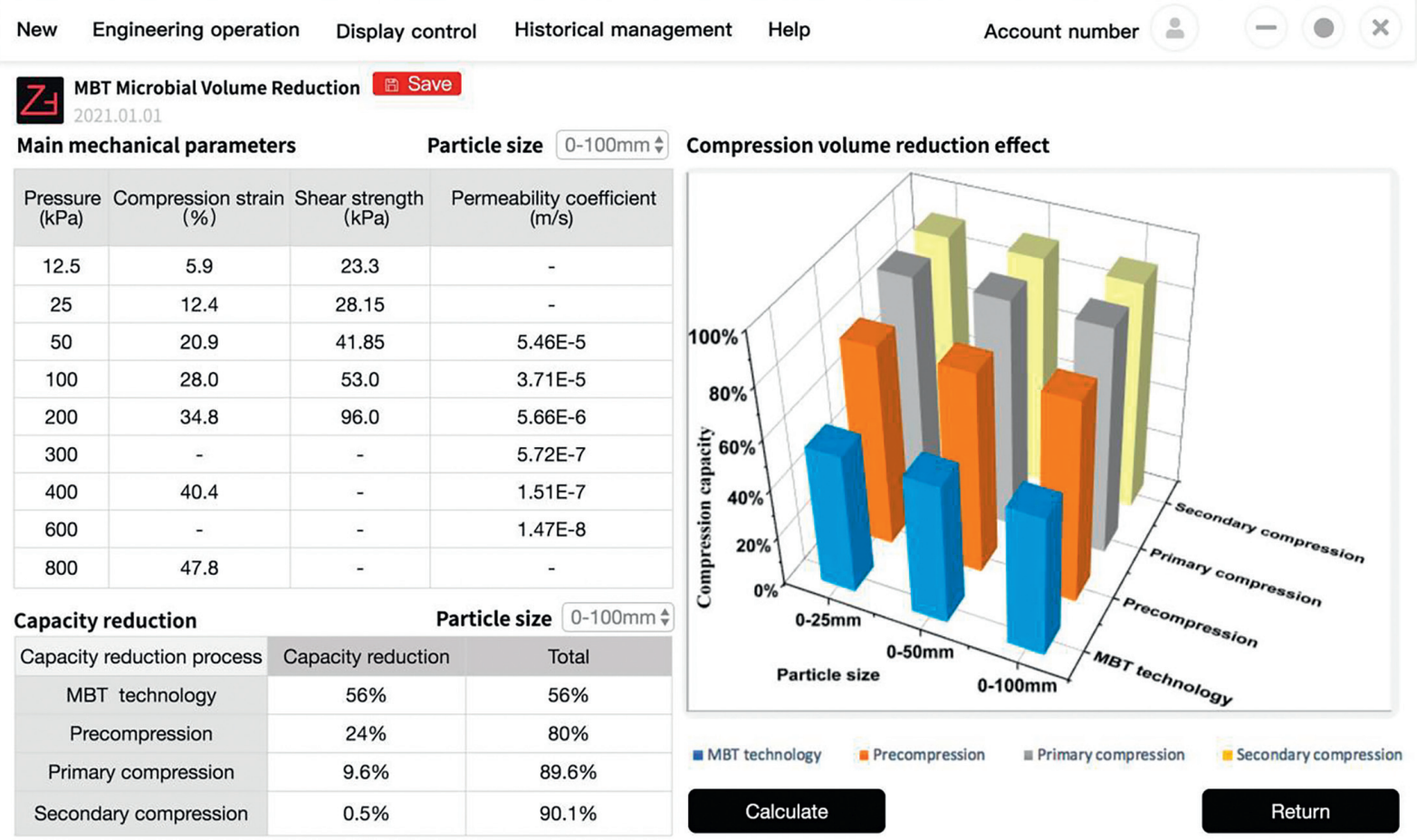

FIgURE 5: MBT microbial volume reduction.

increase the risk of landfill instability. Therefore, domestic waste should be landfilled in layers and zones, and the slope gradient of the landfill should be monitored in real time. Furthermore, the landfill height and slope should be adequately set to reinforce the slope.
Owing to the scale effect, when the landfill height is less than a certain limit value, the stability factor of safety first increases and then decreases with landfill height. When the landfill height exceeds a certain limit, a further height increase causes a significant decrease in slope stability. If the 
landfill height continues to increase, the risk of site instability increases. Therefore, landfill height real-time monitoring and stability analysis are crucial to ensure stable landfill operation. The safety factor of a landfill increases with an increase in the shear strength parameter cohesion and internal friction angle. Therefore, real-time monitoring of shear strength parameters and stability analysis can ensure safe landfill operation.

The main components of landfill gas are methane and carbon dioxide. The leakage of landfill gas will cause a greenhouse effect, air pollution, and fire hazards. Therefore, it is necessary to monitor the leakage of landfill gas in real time.

In conclusion, we analysed the landfill stability based on the leachate level, continuous heavy rainfall, slope, landfill height, shear strength, and landfill gas [31]. The interface diagram of the stability analysis module is shown in Figure 6.

(1) Leachate level. Through the slope and leakage module in the numerical simulation software Geo Studio, the corresponding geometric model is established, the minimum safety factor FS and possible sliding surface of the landfill under different influencing factors are calculated, and the stability of the landfill model is judged. To make the stability analysis of the landfill more comprehensive and scientific, a two-dimensional model of the landfill under different influencing factors is established. The length of the landfill is $200 \mathrm{~m}$. The landfill is divided into shallow waste, middle waste, and deep waste. The height of each layer is $12 \mathrm{~m}$, the landfill thickness of layered operation is $3 \mathrm{~m}$, and the foundation is bedrock with a thickness of $10 \mathrm{~m}$. To analyse the effect of the internal water level of the landfill on the stability of the landfill, the leachate water level is set at 5, 10, $15,20,25$, and $30 \mathrm{~m}$ below the surface garbage. The safety factors calculated by the Bishop method were as follows: $1.109,1.274,1.437,1.523,1.652$, and 1.733 , respectively, when the water level is $5 \sim 30 \mathrm{~m}$ from the top. The safety factor FS increases by $5 \sim 10 \%$ every $5 \mathrm{~m}$ when the water level in the landfill decreases. The safety factor of the landfill stability increases by $5-10 \%$ for a decrease of $5 \mathrm{~m}$ in the leachate level. When the leachate level is $5 \mathrm{~m}$ away from the landfill surface, the safety factor is less than 1.20 , and there is a risk of instability.

(2) Continuous heavy rainfall. The safety factor of landfill stability decreases with increasing rainfall time. In the platform, "continuous 7 days of rainfall" was selected for the simulation, and the safety factor was calculated as 1.084, which represents a risk of instability.

(3) Slope. Landfill slope and soil daily cover have a great effect on the mechanical stability of a landfill $[32,33]$. Steeper slopes lead to lower safety and higher risk of instability. For a slope of $1: 1$, the safety factor was 0.978 , which represents an unstable state [34].

(4) Landfill height. In the platform, "landfill height is more than $60 \mathrm{~m}$ " was selected for simulation, and the safety factor was less than 1.216, which represented a risk of instability.
(5) Shear strength. The stability of the landfill and the stability of waste itself are both related to the shear strength of waste (soil). In the developed platform, when the shear strength parameter cohesion is less than $10 \mathrm{KPa}$ and the internal friction angle is less than $10^{\circ}$, the safety factor of the landfill is 1.102, and the landfill is in an unstable state [35].

(6) Landfill gas. In the platform, "methane concentration is more than $1.25 \%$ " was selected for simulation, and the safety was 1.20 , which represented a risk of instability.

3.2.5. Result Analysis. In this module, the stability calculation of the MBT landfill and waste dam adopts a quadrilateral eight-node element. The "Duncan Chang model" and "effective stress analysis" were selected for the interface, and "fixed bottom and back slope, free top and front slope" were selected as "boundary conditions." The safety factor of the most dangerous sliding surface was 1.532 , and the safety factor of a traditional limit equilibrium method was 1.55 . Therefore, the landfill is in a stable state [36-38].

Limit state hypothesis analysis and early warning of landfills were then conducted. When choosing to "increase the height of leachate by $5 \mathrm{~m}$ on the original basis," a landfill safety factor of 1.32 was obtained, which indicates an unstable state. Therefore, the leachate height should be reduced to improve the stability of the MBT landfill and prevent large-scale landslides. The interface diagram of the results analysis module is shown in Figure 7 [39].

\section{Discussion}

4.1. Closed-Cycle Waste Management System in Germany. The first-generation MBT waste treatment technology in Germany is used to treat $20-30 \%$ of the organic waste, and the remaining $\sim 70 \%$ is landfilled. The second generation of MBT waste treatment technology uses the principle of mechanical separation to separate and utilise the high calorific value substances, such as metals and glasses. The remaining organic matter is sorted again for biological aerobic or anaerobic treatment before landfilling [40-45]. The application of MBT waste treatment technology can achieve the goals of waste reduction, recycling, and safe treatment.

A closed-cycle waste management system is considered a cognitive innovation in the field of waste treatment and is being applied in Germany. The biggest feature of the closedcycle waste management system is that any manufacturer and distributor must conduct strict pretreatment and classification of the generated waste, recycle all recyclable waste, and safely treat the remaining waste. The development of a closed-cycle waste management system in Germany is inseparable from MBT technology.

\subsection{MBT Landfill Smart Management Platform Combining} Internet of Things and Smart Environmental Protection. The project supported by the research is the domestic waste mechanical biological ablation technology project, which is located in the Hangzhou Tianziling landfill. The EMBT originates from German technology. After its introduction, 


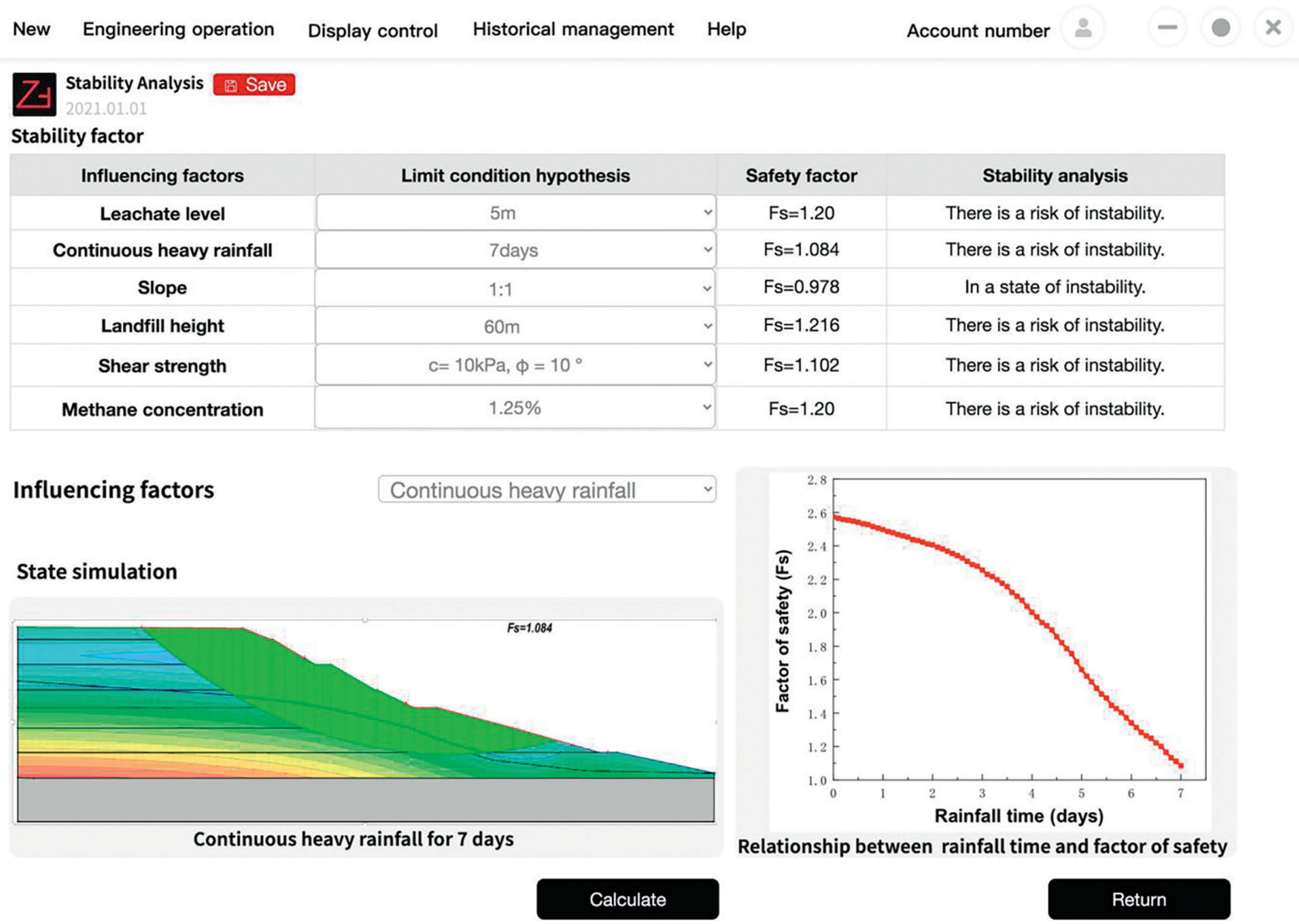

FIgURE 6: Landfill stability analysis.

it will have the opportunity to make improvements and innovations on the characteristics of Chinese waste. The project systematically solves the problem of mixed waste reduction and has strong functions of classification, extraction, and utilisation. It is the third new way of waste endof-end disposal, in addition to landfills and incineration.

Most of the existing landfills in China have low internal organisation and operation efficiency, such as cumbersome workflow and a lack of effective information and communication mechanisms, which directly leads to a risk of reduced work efficiency, ultimately affecting the progress of waste treatment. At the same time, owing to the gradual completion of domestic waste sanitary landfill specifications and standards and the continuous improvement of requirements, the operation cost is increasing and the income cannot meet expectations. Finally, owing to the particularities of the waste treatment project, the normal operation of the project will be affected, to varying degrees, by risk accidents. In this study, we combined the concepts of the Internet of Things and smart environment protection with a "cloud, network, end" platform architecture to construct a smart management platform that can effectively improve the operation and management of landfills, enhance their effective storage volume and service life, and facilitate the sustainable development of cities. The platform can solve problems such as imprecise landfill operation management, substandard pollution prevention, and inadequate disaster prevention.
4.3. Comprehensive Analysis. As a developing country, China's environmental protection efforts are more recent and face the dual task of economic development and environmental protection. At present, the MBT practice in China is not mature, and there is a lack of top-level design and industry debugging for practical applications. Furthermore, there are still no relevant standards and regulations [46].

Regarding waste pretreatment, the investigated closed waste recycling management system in Germany is better than the platform developed in this study. In the German process, the waste disposal process is a closed cycle, with continuous recycling and reuse of waste and a final safe treatment process for waste that cannot be recycled. The front-end pretreatment of waste has social, economic, and ecological benefits, and it can reduce resource waste, treatment costs, and environmental pollution. The development of a closed waste recycling management system in Germany is based on advantageous regulations and advanced technology [47].

Compared with the closed waste cycle management system in Germany, the platform constructed in this study presents two additional modules, MSW production prediction and sharing and communication. The prediction of municipal solid waste production can provide a reference for the efficient allocation of MSW front-end treatment facilities, design of landfill volume, and estimation of service life. However, through the sharing and communication module, 


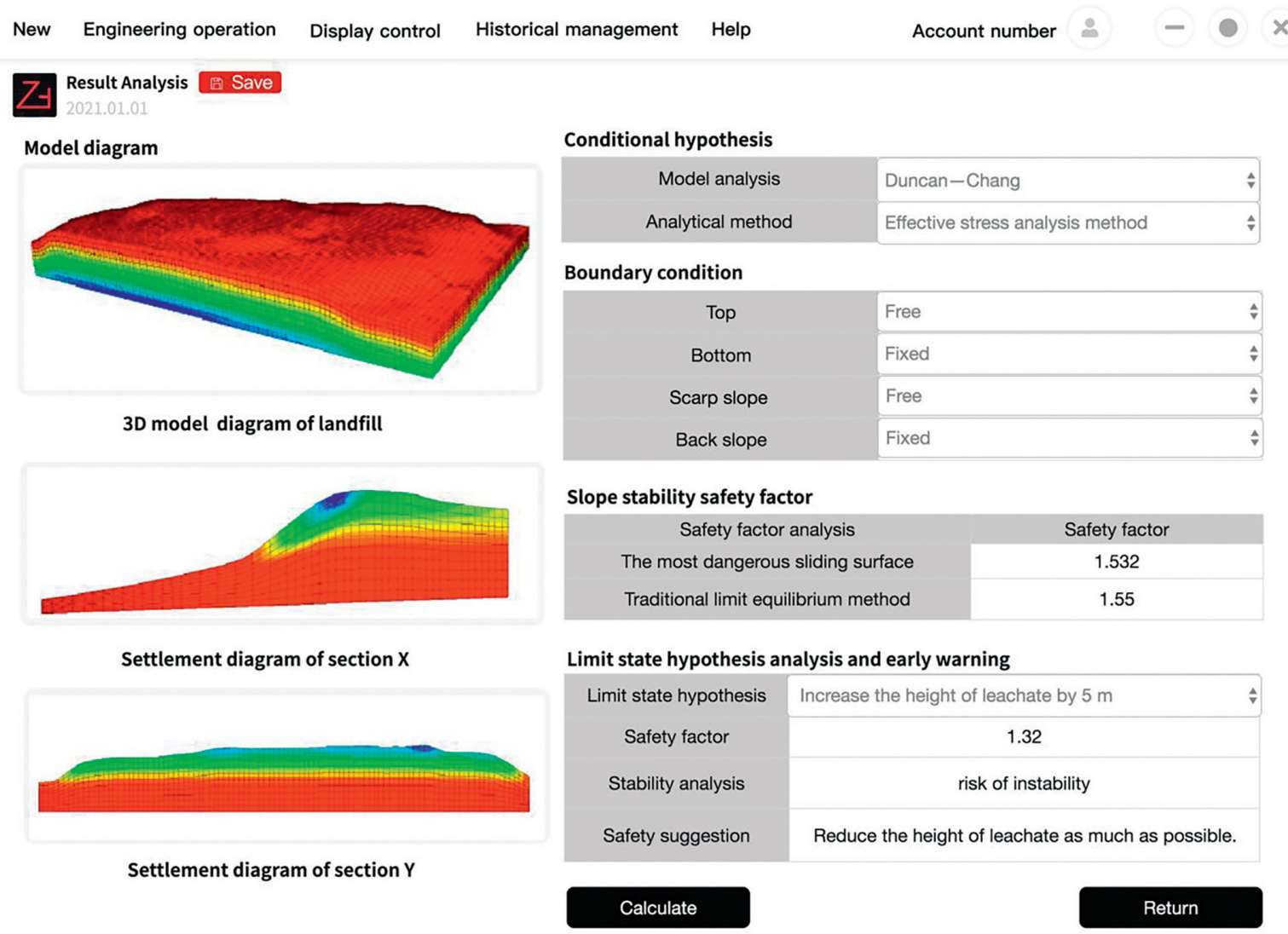

FIGURE 7: Result analysis.

TABLE 1: Mechanical biological treatment (MBT) platform comparison and analysis.

\begin{tabular}{|c|c|c|c|c|}
\hline Platform abbreviation & Landfill type & Characteristics & Advantages & Disadvantages \\
\hline Germany & - & Waste pretreatment & Cycle management & Different national conditions \\
\hline Hangzhou & Valley type & $\begin{array}{l}\text { Smart environmental } \\
\text { protection }\end{array}$ & $\begin{array}{l}\text { (1) Good applicability } \\
\text { (2) Improved stability } \\
\text { (3) Extended service life } \\
\text { (4) Improved management level }\end{array}$ & $\begin{array}{l}\text { (1) Pilot stage } \\
\text { (2) Lack of top-level design } \\
\text { and industrial commissioning }\end{array}$ \\
\hline
\end{tabular}

the public can understand the current waste disposal status and environmental monitoring indicators and make suggestions and complaints in real time to promote the sustainable development of urban areas and an intelligent environmental protection industry. MBT platform comparison and analysis are shown in Table 1.

\section{Conclusions}

This study combined the concept of the Internet of Things and smart environment protection with a "cloud, network, end" platform architecture to construct a smart management platform. The developed platform is composed of seven modules: landfill design, MSW production prediction, MBT microbial volume reduction, stability analysis, result analysis, remote monitoring, and sharing and communication. It can be used to effectively improve the operation and management of waste, enhance the effective storage volume of landfills, and extend their service life, which can contribute to the sustainable development of cities. This study can be used as a reference for similar projects. The main conclusions are as follows:

(1) The risk of landfill instability will be increased by an increase in the leachate level in the landfill, continuous rainfall, slopes that are too steep, landfill heights that are too high, the reduction of shear strength parameters of waste itself, and landfill gas leakage.

(2) The platform uses big data analysis to effectively improve the operation and management level of landfill sites. The platform can provide a volume reduction rate of $90 \%$ for $\mathrm{MBT}$, which greatly improves the effective storage volume of the landfill and extends its service life.

(3) Compared with the closed waste recycling management system in Germany, the developed platform software presents two additional modules, namely, 
the prediction of urban domestic waste output and the sharing module, which are helpful for the development of a sustainable and intelligent waste management platform.

(4) As the MBT waste treatment technology currently adopted in China is still immature, and there is a lack of top-level design and industrial commissioning in practical application, it is hoped that China will issue standards and regulations on this technology as soon as possible.

\section{Data Availability}

The data used to support the findings of this study are included within the article.

\section{Conflicts of Interest}

The authors declare no conflicts of interest.

\section{Acknowledgments}

This research was funded by the National Natural Science Foundation of China (Contract nos. 51978625 and 51678532), supported by the Zhejiang Provincial Natural Science Foundation of China under Grant no. LZ21E080003, and the key Research and Development plan of Zhejiang Province under Grant no. 2021C02039. Thanks are given for the help of the Hangzhou Environmental Group.

\section{References}

[1] S. Shapiro-Bengtsen, F. M. Andersen, and M. Munster, "Municipal solid waste available to the Chinese energy sector? Provincial projections to 2050," Waste Management, vol. 112, pp. 52-65, 2020.

[2] S. Kaza, L. Yao, and P. Bhada-Tata, What a Waste 2.0:a Global Snapshot of Solid Waste Management to 2050, The World Bank, Washington DC, USA, 2018.

[3] T. H. Christensen, A. Damgaard, J. Levis et al., "Application of LCA modelling in integrated waste management," Waste Management, vol. 118, pp. 313-322, 2020.

[4] US Environment Protection Agency, Solid Waste Disposal Facility Criteria: Technical Manual", Office of Solid Waste and Emergency Response, US Environment Protection Agency, Washington, DC, USA, EPA 530-R-93-017, 1993.

[5] Y. Fan and C. Fang, "Assessing environmental performance of eco-industrial development in industrial parks," Waste Management, vol. 107, pp. 219-226, 2020.

[6] Z. P. Qin, "Design and implementation of the application platform of smart environment protection air pollution data," Dissertation, Beijing University of Technology, Beijing, China, 2019.

[7] J. Shi, R. Wang, W. Chen, L. Xing, and M. Jin, "Bi-objective design of household E-waste collection with public advertising and competition from informal sectors," Waste Management, vol. 102, no. 5, pp. 65-75, 2020.

[8] R. Shi, Z. Han, H. Li, S. Wang, N. Guo, and Y. Zhang, "Carbon emission and energy potential of a novel spatiotemporally anaerobic/semi-aerobic bioreactor for domestic waste treatment," Waste Management, vol. 114, pp. 115-123, 2020.
[9] J. W. Lan, R. H. Huang, and K. Gao, "Overview of landfill digital management system," Environmental Sanitation Engineering, vol. 23, no. 6, pp. 52-55, 2015.

[10] B. Munwar Basha and K. V. N. S. Raviteja, "Meethotamulla landfill failure analysis: a probabilistic approach," Geotechnics for Natural and Engineered Sustainable Technologies, Springer, Singapore, pp. 341-351, 2018.

[11] Q. Zhang, "Research on intelligent control system for dynamic monitoring of landfill based on WSN algorithm and 3D-displacemeny collaborative warning model," Dissertation, Chongqing University, Chongqing, China, 2018.

[12] G. Rana, A. Sahar, G. D. Douglas, and M. Ali, "A classification of Hadoop job schedulers based on performance optimization approaches," Cluster Computing, vol. 24, no. 3, pp. 1-23, 2021.

[13] M. U. Hassan, I. Yaqoob, S. Zulfiqar, and I. A. Hameed, "A comprehensive study of HBase storage architecture-A systematic literature review," Symmetry, vol. 13, no. 1, p. 109, 2021.

[14] S. Pablo and S. Ulrich, "Large Elasticsearch cluster management," The European Physical Journal Conferences, vol. 245, no. 8, pp. 7-21, 2020.

[15] J. Kachaoui and A. Belangour, "A multi-criteria Group decision making method for big data storage selection," International Conference on Networked Systems, vol. 11704, 2019.

[16] R. Yang, Z. Xu, and J. Chai, "Seepage analysis of a multilayer waste slope considering the spatial and temporal domains of permeability," Advances in Civil Engineering, vol. 2019, Article ID 3689097, 10 pages, 2019.

[17] Z. Zhang, G. Dai, and Y. Sheng, "Study on the permeability of modified bentonite slurry in landfill," Advances in Materials Science and Engineering, vol. 2020, pp. 1-10, 2020.

[18] L. Fei and Z. X. Jiang, "Tensile failure mechanism of antiseepage system for slope with solid waste underground landfill," Advances in Civil Engineering, vol. 25, pp. 1-8, 2018.

[19] J. McDougall, "A hydro-bio-mechanical model for settlement and other behaviour in landfilled waste," Computers and Geotechnics, vol. 34, no. 4, pp. 229-246, 2007.

[20] M. Dang, J. Chai, Z. Xu, Y. Qin, J. Cao, and F. Liu, "Soil water characteristic curve test and saturated-unsaturated seepage analysis in Jiangcungou municipal solid waste landfill, China," Engineering Geology, vol. 264, Article ID 105374, 2020.

[21] G. M. Filz, J. J. B. Esterhuizen, and J. M. Duncan, "Progressive failure of lined waste impoundments," Journal of Geotechnical and Geoenvironmental Engineering, vol. 127, no. 10, pp. 841-848, 2001.

[22] N. Maeda, J. Tsukahara, K. Endo, M. Kamon, and T. Katsumi, "Seashore MSW landfill using drainage layer and thick soil cover-leachate containment and post-closure land use," in Proceedings of the 8th International Congress on Environmental Geotechnics, pp. 804-811, Hangzhou, China, October 2019.

[23] M. Chang, "Three-dimensional stability analysis of the Kettleman Hills landfill slope failure based on observed slidingblock mechanism," Computers and Geotechnics, vol. 32, no. 8, pp. 587-599, 2005.

[24] H. Ke, P. Ma, J. Lan, Y. Chen, and H. He, "Field behaviors of a geogrid reinforced MSW slope in a high-food-waste-content MSW landfill: a case study," Geotextiles and Geomembranes, vol. 49, no. 2, pp. 430-441, 2021.

[25] X. Qian, R. M. Koerner, and D. H. Gray, "Translational failure analysis of landfills," Journal of Geotechnical and Geoenvironmental Engineering, vol. 129, no. 6, pp. 506-519, 2003.

[26] D. Choudhury and P. Savoikar, "Seismic stability analysis of expanded MSW landfills using pseudo-static limit 
equilibrium method," Waste Management \& Research: The Journal for a Sustainable Circular Economy, vol. 29, no. 2, pp. 135-145, 2011.

[27] T. D. Stark and A. R. Poeppel, "Landfill liner interface strengths from torsional-ring-shear tests," Journal of Geotechnical Engineering, vol. 120, no. 3, pp. 597-615, 1994.

[28] J. Bauer, F. Koelsch, and A. V. A. Borgatto, Stability Analysis According to Different Shear Strength Concepts Exemplified by Two Case Studies, Technical University of Braunschweig, Braunswick, Germany, 2008.

[29] Q. Zhang, Y. Wang, Y. Xu, and R. Li, "Key geotechnical problems in the reconstruction and expansion of existing MSW landfills," China Civil Engineering Journal, vol. 40, no. 4, pp. 73-81, 2007.

[30] Y.-M. Chen and T. L. T. Zhan, "Environmental g related to landfills of municipal solid wastes," Advances in Environmental Geotechnics, Springer, New York, NY, USA, 2010.

[31] H. Sheng, Y. Ren, M. Huang, Z. Zhang, and J. Lan, "Vertical expansion stability of an existing landfill: a case study of a landfill in Xi'an, China," Advances in Civil Engineering, vol. 2021, no. 6, pp. 1-14, 2021.

[32] M. S. Hossain and M. A. Haque, "The effects of daily cover soils on shear strength of municipal solid waste in bioreactor landfills," Waste Management, vol. 29, no. 5, pp. 1568-1576, 2009.

[33] K. T. Ng and I. M Lo, "Fines migration from soil daily covers in Hong Kong landfills," Waste Management, vol. 30, no. 11, pp. 2047-2057, 2010.

[34] G. Blight, "Slope failures in municipal solid waste dumps and landfills: a review," Waste Management \& Research: The Journal for a Sustainable Circular Economy, vol. 26, no. 5, pp. 448-463, 2008.

[35] J. Liu and X. Kong, "Seismic stability and permanent displacement analysis of a solid waste landfill slope containing geomembrane," Rock and Soil Mechanics, vol. 25, no. 5, pp. 778-782, 2004.

[36] R. M. Koerner and T.-Y. Soong, "Stability assessment of ten large landfill failures," Advances in Transportation and GeoEnvironmental Systems Using Geosynthetics, American Society of Civil Engineers, Denver, CO, USA, 2000.

[37] Ain-El-Hammam Municipality, "Algeria," Advances in Civil Engineering, vol. 2019, no. 5, p. 8, 2019.

[38] C. Khoury, K. B. Acheampong, and K. Ofori-Awuah, "Geotechnical modeling of landfill expansion stability," in Proceedings of the 2019 Fourth International Conference on Advances in Computational Tools for Engineering Applications, pp. 1-5, ACTEA, Beirut, Lebanon, July 2019.

[39] S. Decharat, "Heavy metals exposure and hygienic behaviors of workers in sanitary landfill areas in southern Thailand," Scientific, vol. 2016, pp. 1-9, 2016.

[40] G. Tieman, G. Druback, K. Davis et al., "Stability consideration of vertical landfill expansions," Geotechnics of Waste Fills-Theory and Practice. 100 Barr Harbor Drive, PO Box C700, pp. 285-318, ASTM International, West Conshohocken, PA, USA, 1990.

[41] L. Zhang, "Enlightenment of reduction and separation management of municipal solid waste in Germany," Environmental Sanitation Engineering, vol. 26, no. 6, pp. 5-8, 2018.

[42] T. L. T. Zhan, Y. M. Chen, and W. A. Ling, "Shear strength characterization of municipal solid waste at the Suzhou landfill, China," Engineering Geology, vol. 97, no. 3-4, pp. 97-111, 2008.

[43] J. Chen, "Study on the application of rapid collection system of LFG in Shanghai Laogang MSW landfill,"Tsinghua University, Dissertation, Beijing, China, 2017.
[44] S.-L. Shen, B.-H. Wu, H. Xu, and Z.-Y. Zhang, "Assessment of landfill odorous gas effect on surrounding environment," Advances in Civil Engineering, vol. 2020, no. 2, p. 11, 2020.

[45] J.-W. Park and H.-C. Shin, "Surface emission of landfill gas from solid waste landfill," Atmospheric Environment, vol. 35, no. 20, pp. 3445-3451, 2001.

[46] Z. Jin, S. Zhang, L. Hu, C. Fang, D. Shen, and Y. Long, "Effect of substrate sulfur state on MM and DMS emissions in landfill," Waste Management, vol. 116, pp. 112-119, 2020.

[47] S. J. Feng, K. W. Gao, Y. X. Chen, Y. Li, L. M. Zhang, and H. X. Chen, "Geotechnical properties of municipal solid waste at Laogang Landfill," Waste Management, vol. 63, no. 5, pp. 354-365, 2016. 